\section{ORIGINAL RESEARCH}

\author{
S.W. Hetts \\ K. Keenan \\ H.J. Fullerton \\ W.L. Young \\ J.D. English \\ N. Gupta \\ C.F. Dowd \\ R.T. Higashida \\ M.T. Lawton \\ V.V. Halbach
}

\title{
Pediatric Intracranial Nongalenic Pial Arteriovenous Fistulas: Clinical Features, Angioarchitecture, and Outcomes
}

\begin{abstract}
BACKGROUND AND PURPOSE: NGAVFs are rare vascular malformations usually presenting in infancy or childhood. We sought to identify clinical and angiographic predictors of clinical outcome for these lesions.
\end{abstract}

\begin{abstract}
MATERIALS AND METHODS: Retrospective review of a neurointerventional data base identified 386 pediatric patients with intracranial AVFs and AVMs, from which a cohort of 25 patients with NGAVF were selected for medical record and imaging analysis.
\end{abstract}

\begin{abstract}
RESULTS: NGAVFs constituted $7.3 \%$ of pediatric intracranial vascular lesions with a nondural arteriovenous shunt. Seven of 8 patients who presented in the first month of life had CHF and harbored large, complex fistulas with multiple sites of arteriovenous shunting. Single-hole fistulas predominated later in childhood and more frequently presented with seizures, hemorrhage, or focal neurologic deficits. More treatment procedures were performed in subjects presenting at $\leq 2$ years of age compared with older children (median $=3$ versus $2, P=.041$ ), and in those harboring a multi-hole fistula versus those with a single-hole fistula (median $=3$ versus 2, $P=.003$ ). Eighteen patients (72\%) had complete posttreatment elimination of NGAVF shunting. Compared with patients presenting at $>2$ years of age, patients presenting in the first 2 years of life were more likely to have a multi-hole fistula $(100 \%$ versus $25 \%, P=.0001)$ and to have a poor clinical outcome $(54 \%$ versus $0 \%, P=.0052)$, defined as a pediatric $m R S$ of $\geq 3$.
\end{abstract}

CONCLUSIONS: The morbidity of NGAVF appears higher than previously reported despite a somewhat higher rate of angiographic cure. Poor clinical outcome occurred primarily in patients with multi-hole NGAVFs presenting at $\leq 2$ years of age.

\begin{abstract}
ABBREVIATIONS: $\mathrm{AVF}=$ arteriovenous fistula; $\mathrm{CHF}=$ congestive heart failure; DAVF $=$ dural arteriovenous fistula; HHT = hereditary hemorrhagic telangiectasia syndrome; mRS = modified Rankin Scale; $n$-BCA = n-butyl cyanocrylate; NGAVF = nongalenic arteriovenous fistula; VOGM = vein of Galen malformation
\end{abstract}

$\mathbf{N}$ GAVF-also known as intracranial pial AVF, cerebral AVF, or brain AVF-is a rare vascular malformation. Sometimes considered a subset of AVM, NGAVFs are distinct in that 1 or more pial arteries feeds directly into a cortical vein without the intervening nidus of a typical AVM. ${ }^{1,2}$ Venous drainage varies with the location of the fistula. An NGAVF is distinguished from a DAVF by the location of the fistula site in the subpial meningeal space, and from a VOGM by the lack of direct involvement of the embryonic median prosencephalic vein. $^{2}$

The incidence and prevalence of NGAVFs are unknown. In

Received September 30, 2011; accepted after revision December 5

From the Departments of Radiology and Biomedical Imaging (S.W.H., K.K., J.D.E., C.F.D., R.T.H., V.V.H.), Neurology (H.J.F., W.L.Y., J.D.E., C.F.D., R.T.H., V.V.H.), Anesthesia and Perioperative Care (W.L.Y., N.G., C.F.D., R.T.H., M.T.L., V.V.H.), and Neurological Surgery (W.L.Y., C.F.D., R.T.H., V.V.H.), University of California-San Francisco, San Francisco, California.

Supported in part by grants from the Foundation of the American Society of Neuroradiology and the National Institutes of Health R01 NS034949, P01 NS044155, and R01 EB012031.

Data previously presented in part at: Annual Meeting of the American Society of Neuroradiology, June 5-9, 2011; Seattle, Washington.

Please address correspondence to Steven W. Hetts, MD, Neurointerventional Radiology, 505 Parnassus Ave, L-352, San Francisco, CA 94143-0628; e-mail: steven.hetts@ucsf.edu

Indicates open access to non-subscribers at www.ajnr.org

Indicates article with supplemental on-line tables.

http://dx.doi.org/10.3174/ajnr.A3194

previously published series of pediatric and adult subjects from quaternary referral sites at University of California-San Francisco and the Mayo Clinic (Rochester, Minnesota), NGAVFs comprised $1.6 \%$ and $4.7 \%$ of AVMs, respectively. ${ }^{3,4}$ In a recent series of NGAVFs from the Hospital Bicetre (Le Kremlin-Bicetre, Paris, France), 52 cases were identified from a larger group of 620 pediatric brain AVMs $(8.4 \%){ }^{5,6} \mathrm{~A}$ total of 168 cases in children and adults has been reported since 1970. ${ }^{5-14}$ Assuming that these centers have an enriched sample of NGAVFs, and the population prevalence of brain AVM is roughly $10 / 100,000,{ }^{15}$ then the prevalence of NGAVFs can be estimated to be $0.1 / 100,000$ to $1 / 100,000$.

NGAVFs usually become symptomatic in childhood. The most common presentation of NGAVF in neonates is CHF. Infants may present with increased head circumference or focal neurologic deficits. Adolescents and adults more often have headaches, seizures, and focal neurologic deficits. ${ }^{1,45,16}$ The goal of treatment for an NGAVF is occlusion of the AVF site or of the feeding arteries and proximal draining vein as close to the fistula as possible. Prognosis is considered to be poorer with conservative management, and treatment is usually attempted unless significant brain damage has already occurred. ${ }^{1,5,17}$

The purpose of this single-institution retrospective cohort study was to compare the clinical presentation, angioarchitecture, and treatment outcomes of children with NGAVFs pre- 


\begin{tabular}{|c|c|c|c|c|}
\hline & $\begin{array}{c}\text { All Subjects } \\
n=25\end{array}$ & $\begin{array}{c}\text { Single-Hole Fistulas } \\
n=9\end{array}$ & $\begin{array}{c}\text { Multi-Hole Fistulas } \\
n=16\end{array}$ & $P$ Value \\
\hline \multicolumn{5}{|l|}{ Baseline clinical characteristics } \\
\hline Mean age \pm SD & $4.2 \pm 5.3 y$ & $8 \pm 4.5 y$ & $2.1 \pm 4.6 y$ & .0065 \\
\hline Median age (range) & 1.2 y (1 day to 16 y) & 7 y $(3-14$ y) & 45 days ( 1 day to 16 y) & \\
\hline Male & $56 \%$ & $56 \%$ & $56 \%$ & 1.0 \\
\hline CHF & $32 \%$ & $0 \%$ & $44 \%$ & .027 \\
\hline Seizures & $32 \%$ & $44 \%$ & $25 \%$ & .39 \\
\hline Current or prior hemorrhage & $16 \%$ & $33 \%$ & $6.3 \%$ & .12 \\
\hline Focal neurological deficit & $24 \%$ & $11 \%$ & $31 \%$ & .36 \\
\hline Any comorbidity or risk factor & $48 \%$ & $22 \%$ & $63 \%$ & .097 \\
\hline \multicolumn{5}{|l|}{ Baseline angioarchitecture } \\
\hline$>1$ brain vascular lesion & $32 \%$ & $22 \%$ & $38 \%$ & .66 \\
\hline Feeding artery aneurysm(s) & $8 \%$ & $22 \%$ & $0 \%$ & .12 \\
\hline$>1$ arterial territory involved & $52 \%$ & $11 \%$ & $75 \%$ & .036 \\
\hline Any deep venous drainage & $40 \%$ & $22 \%$ & $50 \%$ & .23 \\
\hline$>1$ draining vein from any lesion & $48 \%$ & $44 \%$ & $56 \%$ & .69 \\
\hline Massive venous sinus dilation & $23 \%$ & $0 \%$ & $31 \%$ & .12 \\
\hline Any venous sinus dilation & $41 \%$ & $13 \%$ & $57 \%$ & .074 \\
\hline Vein of Galen dilation & $26 \%$ & $0 \%$ & $40 \%$ & .12 \\
\hline
\end{tabular}

senting in the first 2 years of life, in whom cardiovascular symptoms are predominant, with those presenting later in childhood (between 2 and 18 years of age), in whom neurologic symptoms are predominant.

\section{Materials and Methods}

\section{Subjects}

In this institutional review board-approved study, a neurointerventional radiology data base was used to identify a cohort of 386 patients $\leq 18$ years of age who had undergone evaluation and treatment for intracranial arteriovenous shunt at University of California-San Francisco between 1986 and 2011. Data were cross-checked with a larger institutional brain AVM data base for cases between 2000 and 2011. Imaging reports and medical records of patients with diagnoses of NGAVF, DAVF, VOGM, and AVM were reviewed. Twenty-eight patients with an NGAVF were identified, including 7 who had been included in other published reports (patients 3,10,11, 17, 19, 20, and 23 of the current series; On-line Table 1). ${ }^{18-21}$ Three patients were excluded due to insufficient clinical and imaging data to confirm the diagnosis of NGAVF.

\section{Medical Record Review}

Baseline variables were recorded for each subject (On-line Table 1). Angioarchitectural characteristics identified from initial pretreatment angiograms are noted in On-line Tables 2 and 3. Single-hole fistulas were defined as 1 arteriovenous connection and multi-hole fistulas defined as $>1 \mathrm{AV}$ connection. Dural venous sinus dilation was defined as double the expected diameter of a given dural venous sinus, based on angiograms of children of similar ages at our institution without arteriovenous shunting. Treatment and outcome variables are outlined in On-line Table 4.

\section{Imaging Review}

Preintervention diagnostic cerebral angiograms and accompanying reports were available for 19 of 25 patients. These angiographic images were reviewed and scored according to a structured data collection sheet previously developed for brain $\mathrm{AVMs}^{22}$ and modified to highlight features of NGAVFs. One additional patient was scored from images acquired after a prior embolization. Two patients were scored using images from their published case reports as well as angiography reports. If inconsistencies existed between angiographic images and radiology reports, the images were reviewed and those results were used for definitive scoring. Three patients were reviewed using only structured angiography reports, which are of the same format and authored by the same group of angiographers for the entire study period. To explore the possibility of bias from inclusion of the 3 patients scored from reports, we performed sensitivity analysis on the data excluding these patients. There were no significant changes in effect sizes or significance levels (data not shown).

\section{Treatment}

Patients were treated by endovascular intervention, a combination of endovascular and surgical intervention, radiosurgery, or observation. Our institution's overall approach to the management of patients with NGAVFs is described below.

\section{Outcomes Assessment}

Medical records from each patient's last clinical follow-up were assessed by 3 investigators (S.H., K.K., J.D.E.) for neurologic or developmental disability; any initial disagreements were resolved by consensus. A previously developed adaptation of the mRS of neurologic disability for use in pediatric patients with brain $\mathrm{AVMs}^{23}$ was used for retrospective classification of initial clinical function and ultimate clinical outcome in all patients. For patients presenting at $<1$ year of age, an initial mRS score was not assigned, as application of that scale to such young patients is of limited value. Good clinical outcome was defined as a pediatric mRS of $0-2$. At the time of last follow-up, records and images were assessed by 2 investigators (S.H., K.K.) for evidence of residual arteriovenous shunting. Follow-up duration was the time from clinical presentation to last clinical or imaging report.

\section{Statistical Analysis}

In a descriptive analysis, patients were stratified by sex as well as by age of presentation: neonates, infants, and young children presenting at $\leq 2$ years of age compared with older children presenting at $>2$ years of age. Patients were also stratified by fistula complexity: simple single-hole AVFs versus complex multi-hole AVFs (Tables 1 and 2). 
Table 2: Treatments and outcomes stratified by fistula complexity

\begin{tabular}{|c|c|c|c|c|}
\hline & $\begin{array}{c}\text { All Subjects } \\
n=25\end{array}$ & $\begin{array}{c}\text { Single-Hole Fistulas } \\
n=9\end{array}$ & $\begin{array}{c}\text { Multi-Hole Fistulas } \\
n=16\end{array}$ & $P$ Value \\
\hline \multicolumn{5}{|l|}{ Treatments } \\
\hline Mean age of first treatment $\pm S D$ & $4.9 \pm 6.5 y$ & $9.4 \pm 7.3 y$ & $2.3 \pm 4.5 y$ & .021 \\
\hline Median age (range) of first treatment & 1.7 y (1 day to 25 y) & 7 y $(3-25 y)$ & 0.62 y (1 day to 16 y) & \\
\hline Median treatment procedures (range) & $2(1-5)$ & $2(1-2)$ & $3(1-5)$ & .003 \\
\hline Endovascular treatments only & $60 \%$ & $67 \%$ & $56 \%$ & .69 \\
\hline Any periprocedural complication & $60 \%$ & $22 \%$ & $81 \%$ & .009 \\
\hline Any symptomatic complication & $32 \%$ & $22 \%$ & $38 \%$ & .66 \\
\hline \multicolumn{5}{|l|}{ Outcomes at last follow-up } \\
\hline Mean follow-up duration \pm SD & $3.3 \pm 3.3 y$ & $4.3 \pm 4.1 \mathrm{y}$ & $2.7 \pm 2.6 y$ & .33 \\
\hline Median (range) follow-up duration & 2 y (1 day to 13 y) & 4 y (2 days to 13 y) & 1.8 y (1 day to 7 y) & \\
\hline Occlusion of all targeted arteriovenous shunts & $72 \%$ & $78 \%$ & $69 \%$ & 1.0 \\
\hline Elimination of all arteriovenous shunting & $60 \%$ & $78 \%$ & $38 \%$ & .097 \\
\hline White matter calcifications & $25 \%$ & $0 \%$ & $35 \%$ & .26 \\
\hline Normal neurologic examination & $48 \%$ & $100 \%$ & $19 \%$ & .0001 \\
\hline Median last mRS (range) & $1(0-6)$ & $0(0)$ & $2(0-6)$ & $<.0001$ \\
\hline Good outcome (last mRS 0-2) & $72 \%$ & $100 \%$ & $56 \%$ & .027 \\
\hline
\end{tabular}

Table 3: Presentation and fistula angioarchitecture stratified by age of presentation and by patient gender

\begin{tabular}{|c|c|c|c|c|c|c|c|}
\hline & \multicolumn{4}{|c|}{ Age } & \multicolumn{3}{|c|}{ Gender } \\
\hline & $\begin{array}{c}\text { All Subjects } \\
n=25\end{array}$ & $\begin{array}{c}\leq 2 \text { Years 0ld a } \\
\text { Presentation } \\
n=13\end{array}$ & $\begin{array}{c}>2 \text { Years Old at } \\
\text { Presentation } \\
\quad n=12\end{array}$ & $P$ Value & $\begin{array}{l}\text { Males } \\
n=14\end{array}$ & $\begin{array}{c}\text { Females } \\
n=11\end{array}$ & $\begin{array}{c}P \\
\text { Value }\end{array}$ \\
\hline \multicolumn{8}{|l|}{ Baseline clinical characteristics } \\
\hline Mean age $\pm S D$ & $4.2 \pm 5.3 y$ & & & & $3.6 \pm 5.2 y$ & $5.1 \pm 5.7 y$ & .51 \\
\hline Median age (range) & 1.2 y (1 day to 16 y) & & & & 0.62 y (1 day to 14 y) & ) 3.0 y (21 days to 16 y & \\
\hline Male & $56 \%$ & $62 \%$ & $50 \%$ & .70 & & & \\
\hline $\mathrm{CHF}$ & $32 \%$ & $62 \%$ & $0 \%$ & .0016 & $43 \%$ & $9.1 \%$ & .09 \\
\hline Seizures & $32 \%$ & $23 \%$ & $42 \%$ & .41 & $29 \%$ & $36 \%$ & 1.0 \\
\hline Current or prior hemorrhage & $16 \%$ & $7.7 \%$ & $25 \%$ & .32 & $7.1 \%$ & $27 \%$ & .29 \\
\hline Focal neurologic deficit & $24 \%$ & $31 \%$ & $8.3 \%$ & .32 & $21 \%$ & $27 \%$ & 1.0 \\
\hline Median (range) presentation mRS & & & $2.5(0-5)$ & & & & \\
\hline Any identified comorbidity or risk factor & $48 \%$ & $69 \%$ & $25 \%$ & .047 & $43 \%$ & $55 \%$ & .70 \\
\hline \multicolumn{8}{|l|}{ Baseline angioarchitecture } \\
\hline$>1$ arteriovenous connection & $64 \%$ & $100 \%$ & $25 \%$ & .0001 & $64 \%$ & $64 \%$ & 1.0 \\
\hline$>1$ brain vascular lesion & $32 \%$ & $31 \%$ & $33 \%$ & 1.0 & $21 \%$ & $45 \%$ & .39 \\
\hline Feeding artery aneurysm(s) & $8 \%$ & $0 \%$ & $17 \%$ & .22 & $14 \%$ & $0 \%$ & .49 \\
\hline$>1$ arterial territory involved & $52 \%$ & $85 \%$ & $17 \%$ & .0012 & $57 \%$ & $45 \%$ & .70 \\
\hline Any deep venous drainage in any lesion & $40 \%$ & $54 \%$ & $25 \%$ & .23 & $43 \%$ & $36 \%$ & 1.0 \\
\hline$>1$ draining vein from any lesion & $48 \%$ & $38 \%$ & $58 \%$ & .43 & $43 \%$ & $64 \%$ & .43 \\
\hline Massive venous sinus dilation & $23 \%$ & $45 \%$ & $0 \%$ & .035 & $36 \%$ & $0 \%$ & .046 \\
\hline Any venous sinus dilation & $41 \%$ & $64 \%$ & $18 \%$ & .081 & $57 \%$ & $9.1 \%$ & .033 \\
\hline Vein of Galen dilation & $26 \%$ & $42 \%$ & $9.1 \%$ & .16 & $29 \%$ & $18 \%$ & .66 \\
\hline
\end{tabular}

Student $t$ tests were used to compare normally distributed continuous data, Wilcoxon rank sum tests were used to compare ordinal data, and Fisher exact tests were used to compare proportions. Descriptive statistics and Student $t$ tests were calculated in Excel for Macintosh 2008 (Microsoft, Redmond, Washington). Risk ratios, 95\% confidence intervals, odds ratios, and Wilcoxon rank sum and Fisher exact tests were performed in Stata SE version 11 (StataCorp, College Station, Texas).

\section{Results}

\section{Demographic Information}

NGAVFs were present in $7.3 \%$ of the 386 pediatric patients evaluated and treated for intracranial arteriovenous shunting at our hospital during the study period. Of the 25 patients included for further analysis, 14 were boys and 11 were girls. Whereas boys presented clinically at a median age of 8 months (range, 1 day to 14 years), girls presented at a median age of 3 years (range, 21 days to 16 years). Baseline patient characteristics and clinical presentations are presented in Tables 1 and 3, and in On-line Table 1.

\section{Clinical Presentation}

Clinical presentation varied by age (Table 3 ) but was similar in boys and girls. One girl was diagnosed with intracranial AVF and associated hydrops fetalis by sonography in utero. Another girl received prenatal diagnosis of intracranial AVF when a hypervascular intracranial mass was identified in the setting of a twin pregnancy. Eight patients presented as neonates ( $<1$ month of age), 5 presented in later infancy or the second year of life ( 1 month to 1.3 years old), and 12 presented later in childhood (3-16 years of age). Neonates most often presented with manifestations of high output cardiac failure: 
CHF (7/8), pulmonary hypertension (5/8), cyanosis, (2/8), anasarca $(2 / 8)$, liver failure $(2 / 8)$, renal failure $(1 / 8)$, or disseminated intravascular coagulation (1/8). Four neonates had audible cranial bruits. Neurologic deficits (hypotonia, hemiparesis), hydrocephalus, and skin lesions (facial AVM, scalp cutis aplasia) were less common.

Of the 5 patients who presented in infancy or the second year of life, 3 had seizures, 3 had neurologic deficits (cranial neuropathy, nystagmus, hypotonia), 2 had developmental delay, 2 had macrocephaly or hydrocephalus, 2 had audible cranial bruits, 1 had dilated facial veins, and 1 had mild CHF. CHF was more likely to manifest in neonates than in infants and children (risk ratio $=15 ; 95 \% \mathrm{CI}, 2.2$ to $101 ; P=.0001$ ).

Twelve children 2 years and older came to attention due to headaches $(50 \%)$, seizures $(42 \%)$, intracranial hemorrhage (25\%), lethargy (17\%), visual changes (17\%), or other signs or symptoms ( $8 \%$ each: coma, hydrocephalus, macrocephaly, vomiting, monoparesis). Seizures were more common in children and infants than in neonates $(47 \%$ versus $0 \%$, respectively, $P=.026)$. All 4 patients presenting with intracranial hemorrhage were infants or children; no neonates presented with hemorrhage. The median presentation $\mathrm{mRS}$ for children $>2$ years was 2.5 , with a range of $0-5$.

Patients with multi-hole fistulas presented at younger ages than those with single-hole fistulas (Table 1). CHF also occurred more frequently in subjects with multi-hole fistulas than in those with single-hole fistulas. Current or prior intracranial hemorrhage in patients with single-hole fistulas was more common than in those with multi-hole fistulas, though this trend did not reach statistical significance $(P=.12)$.

Risk factors for AVF formation, as well as comorbidities associated with arteriovenous shunting, were identified in several patients (On-line Table 1). One patient had hydrops fetalis, due to arteriovenous shunting diagnosed in utero. Several of the patients' mothers had obstetric complications that may have been related to lesser degrees of underlying fetal CHF. These complications included pre-eclampsia, fetal bradycardia, and failure to progress in labor. One patient had a father with a brain aneurysm and a cousin with multiple brain AVMs. Three patients were born with congenital malformations: 1 with cutis aplasia and a facial AVM, 1 with parietal schizencephaly, and 1 with hydrocele and penile urethral defect. One patient with 3 separate brain AVFs was diagnosed with HHT.

\section{Angioarchitecture}

The angioarchitecture of NGAVF varied among different age groups (Table 3). Complex fistulas with multiple arteriovenous connections (including the presence of multiple single-hole lesions) were more common in subjects presenting in the first 2 years of life (100\%; Figs 1 and 2) than in older children $(25 \%, P=.0001)$, while single-hole fistulas were more common in older children (Fig 3). Arterial and venous angioarchitectural features are described in On-line Tables 2 and 3. In keeping with the presentation of complex fistulas earlier in life, subjects presenting in the first 2 years of life $(85 \%)$ were more likely than older children $(17 \%)$ to harbor fistulas fed by more than 1 arterial territory (risk ratio $=5.1$; 95\% CI, 1.4 to $18 ; P=.0012)$. Feeding artery aneurysms were identified in 2 older children (15\%) but not in any children presenting at $\leq 2$ years of age. There was no significant difference in the presence of deep versus superficial venous drainage, nor in the number of draining veins when neonates and infants were compared with children. Venous sinus dilation was more common in boys $(57 \%)$ than in girls $(9 \%, P=.033)$.

\section{Treatment}

Treatments, procedural complications, and imaging and clinical outcomes are described in Tables 2 and 4 . The median age at first treatment was 9 months for boys and 3 years for girls. Patients received between 1 and 5 endovascular, surgical, or radiosurgical treatments, with a median of 2 treatments. Subjects presenting at $\leq 2$ years of age underwent more treatment procedures than did children presenting at $>2$ years of age (median 3 versus 2, $P=.041$ ). Similarly, patients with multihole fistulas received more treatments than those with singlehole fistulas (median 3 versus $2, P=.003$ ).

The treatment for each patient is detailed in On-line Table 4. Patients were treated by an endovascular route using a variety of materials: coils, $24 / 25$ patients $(96 \%)$; $n$-BCA glue, 2/25 (8\%); particulate emboli, 2/25 (8\%); and a detachable balloon, 1/25 (4\%). Three patients with DAVFs identified 3 months to 3.5 years after initial NGAVF treatment were also treated transarterially with $n$-BCA glue ( 1 patient) or absolute ethanol (2 patients). Ten patients received surgery after endovascular embolization that was either incomplete (9 of 10) or unsuccessful ( 1 patient with a pushable coil-from the era before detachable coils were available-lost to the draining vein of the AVF). One patient received stereotactic gamma knife (Leskell, Sweden) radiosurgery to a small AVM nidus that became apparent only after a large nearby NGAVF was embolized.

\section{Procedural Complications}

Overall, 15/25 (60\%) patients experienced a procedural or periprocedural complication of any type, 8/25 (32\%) had a symptomatic complication, and $3 / 25(12 \%)$ suffered a major complication (defined as death, permanent neurologic deficit, or a complication requiring urgent surgical intervention). On a per-procedure basis, the complication rate was 30\% (18 complications in 60 procedures). Among endovascular and surgical complications, 3 were major (death due to intraprocedural basilar artery rupture, large postsurgical intracerebral hemorrhage, common femoral artery transection requiring surgical repair), 8 were minor or transient (urinary tract infection, lower extremity embolus not requiring treatment, seizures, cerebral edema, transient focal neurologic deficits, postoperative fever, myelopathy), and 7 were asymptomatic (microcatheter- or microwire-induced vascular perforations sealed intraprocedurally without associated clinical decline, lower extremity embolus, small parietal lobe infarction).

The likelihood of complications varied by patient age and complexity of vascular lesion. All 3 major complications occurred in treated patients $<1$ year of age. Based on age of presentation, having any complication was more likely in subjects presenting at $\leq 2$ years of age $(85 \%)$ than in children presenting at $>2$ years of age $(33 \%$; risk ratio $=3.3 ; 95 \% \mathrm{CI}$, 0.94 to $12 ; P=.015)$. The likelihood of having a symptomatic complication, however, did not differ between age groups. Patients with single-hole fistulas were less likely to have any com- 

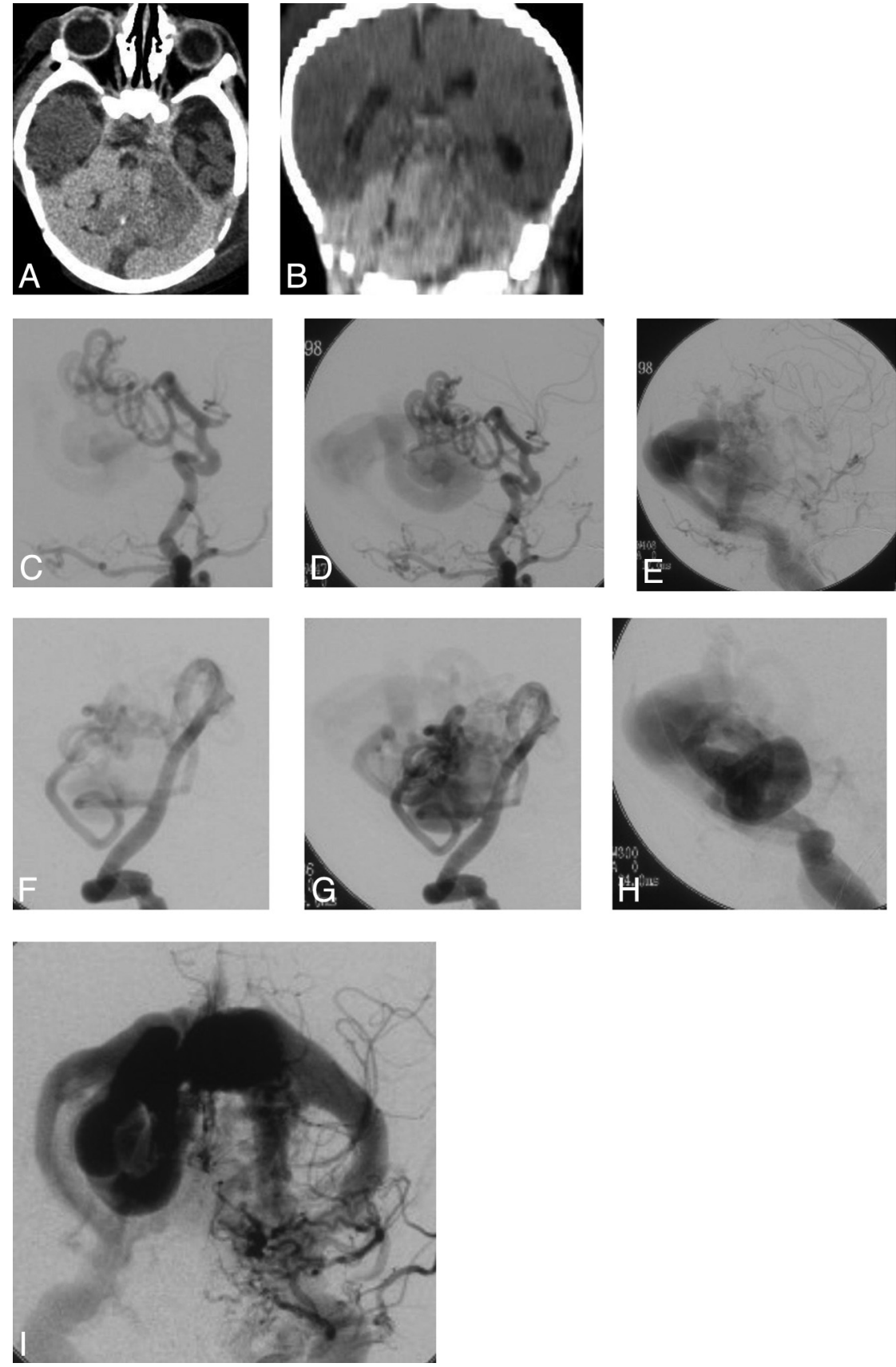

Fig 1. Giant multi-hole AVF (patient 4). A full-term boy presented at birth with CHF. Neonatal axial $(A)$ and coronally reformatted $(B)$ CECT images suggest a large vascular malformation occupying most of the posterior fossa. DSA at 9 days of life $(C-E$, early, mid, and late phase left CCA injections in the lateral projection; $F-H$, early, mid, and late left vertebral artery injections in the AP lateral projection) identifies a large multi-hole pial AVF supplied principally from the PCA and choroidal arteries, draining to markedly dilated posterior fossa veins and subsequently into dilated dural venous sinuses (I, late phase left CCA injection). After undergoing 4 embolization sessions in the first month of life, the patient had resolution of CHF and ultimately made a good clinical recovery with mild developmental delay and cerebellar dysfunction at last follow-up at age 8 years. CCA indicates common carotid artery; CECT, contrast enhanced CT; PCA, posterior cerebral artery.

plication (22\%) than those with multi-hole fistulas (81\%; risk ratio $=0.19 ; 95 \% \mathrm{CI}, 0.049$ to $0.74 ; P=.009)$.

\section{Imaging and Clinical Outcomes}

The mean time to the last imaging follow-up was $3.3 \pm 3.3$ years for all patients, with a median of 2 years (Tables 2 and 4 ). Eighteen of 25 patients (72\%) had complete elimination of arteriovenous shunting within the targeted NGAVF at last follow-up. Four boys who originally presented with multi-hole NGAVFs eventually developed apparently new intracranial
DAVFs during the course of follow-up; 2 of these DAVFs were subsequently completely embolized and 2 were not (On-line Table 4). Overall, 15/25 (60\%) of patients had elimination of all sites of intracranial arteriovenous shunting at the time of last imaging follow-up. There was a trend for boys to develop cerebral white matter calcifications-often attributed to chronic venous hypertension-more frequently than girls ( $42 \%$ versus $0 \%$, respectively, $P=.055$ ).

The mean time to last clinical follow-up was $3.3 \pm 3.3$ years for all patients, with a median of 2 years (Tables 2 and 4 ). Two 

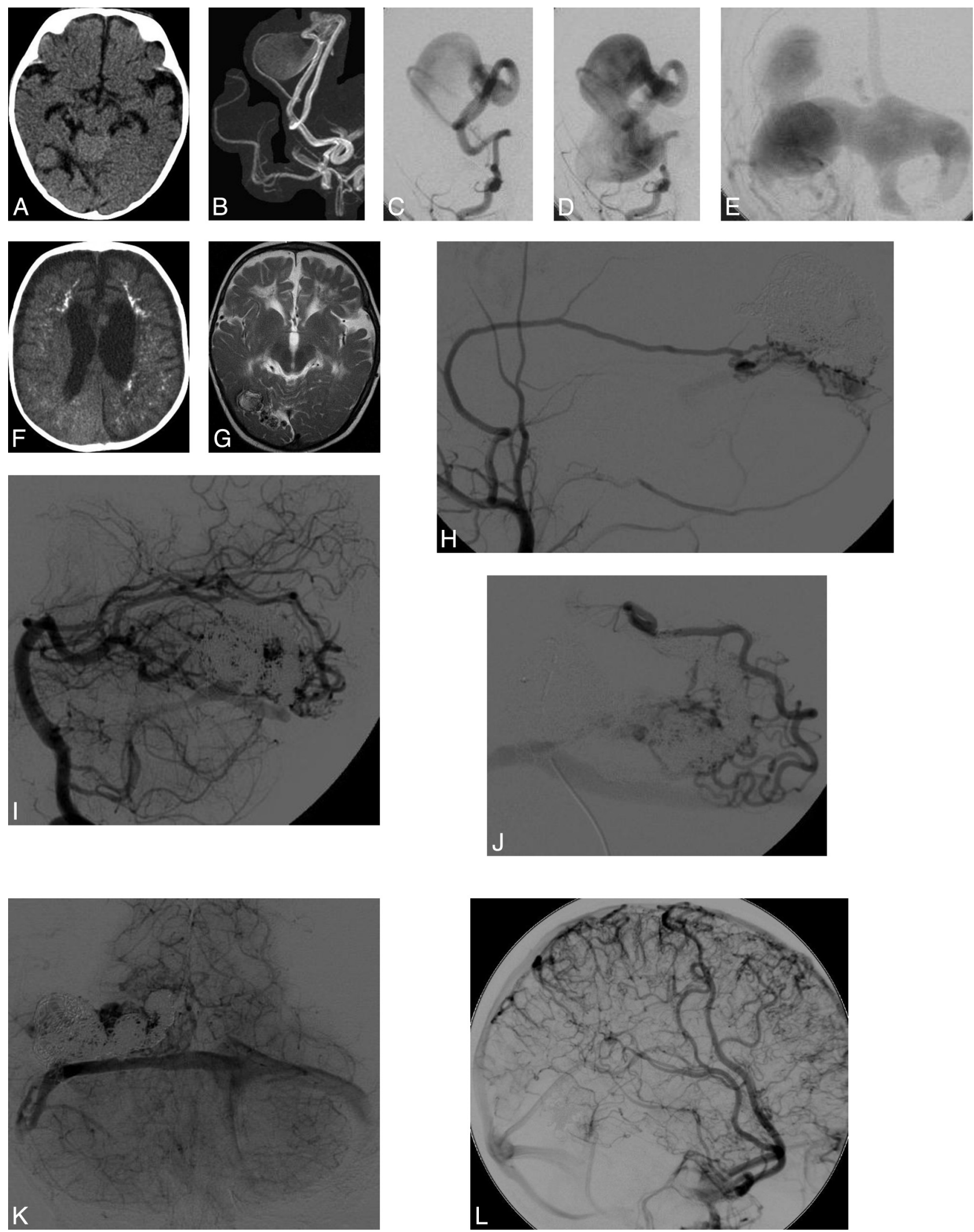

Fig 2. Multi-hole AVF with delayed white matter calcifications and DAVF formation (patient 9). A 2-month-old boy presented with seizures, hypotonia, developmental delay, and nystagmus. A NECT at 2 months of age demonstrates a mass in the right temporal lobe $(A)$ and no white matter calcifications. MRA (B) suggests an AVF involving the right PCA. DSA at 6 months of age (C) confirms 3 PCA branch shunting to a single markedly enlarged vein with associated marked venous sinus dilation $(D, E$. Initial transarterial coil embolization eliminated arteriovenous shunting, but a follow-up NECT at age 6 months demonstrates development of extensive white matter calcifications $(A$, and a T2-weighted MR imaging $(G)$ at age 18 months demonstrates extensive white matter damage, both likely due to the patient's pre-embolization period of cerebral venous hypertension. A follow-up angiogram at age 3 years demonstrates de novo dural supply to the AVF from hypertrophied MMA and ascending pharyngeal artery $(H)$, as well as recurrent mild shunting from small branches of the PCA $(I, I)$. At that same time, DSA demonstrates resolution of venous sinus dilation $(K)$. One year after ethanol embolization of the noneloquent distal anterior division MMA supply and surgical resection of the occipital fistula, no residual shunting was present but a pseudophlebitic pattern of medullary venous drainage was still evident (L). MMA indicates middle meningeal artery; NECT, nonenhanced CT; PCA, posterior cerebral artery. 

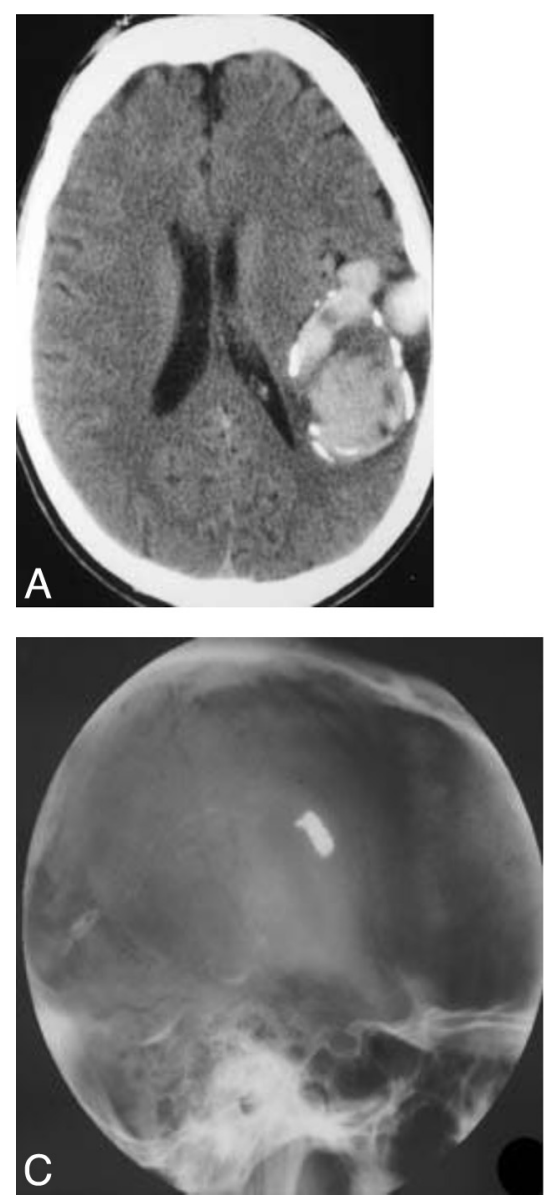
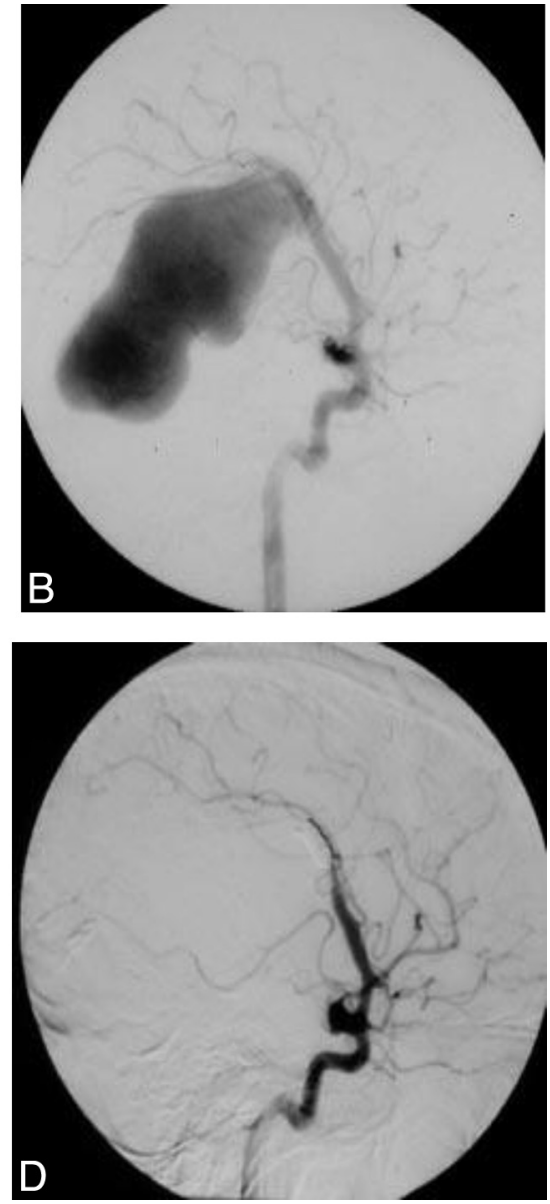

Fig 3. Single-hole AVF with giant varix (patient 23). A 13-year-old boy was diagnosed with a pial AVF after presenting with a seizure. His family chose medical therapy with anticonvulsants. At age 25 years, the patient's seizure frequency increased and he elected endovascular treatment of his fistula. Contrast-enhanced CT just before treatment ( $A$ ) demonstrates a giant left parietal venous varix with mural calcifications. Left ICA injection lateral projection DSA (B) shows a single hypertrophied MCA cortical feeding artery supplying a single-hole AVF, with an associated giant venous varix. After endovascular coiling, a lateral $x$-ray $(C)$ demonstrates the coil mass in place at the arteriovenous connection and a left ICA lateral DSA (D) confirms elimination of arteriovenous shunting. ${ }^{38}$

Table 4: Treatments and outcomes stratified by age of presentation and by patient gender

\begin{tabular}{|c|c|c|c|c|c|c|c|}
\hline & \multicolumn{4}{|c|}{ Age } & \multicolumn{3}{|c|}{ Gender } \\
\hline & $\begin{array}{l}\text { All Subjects } \\
\quad n=25\end{array}$ & $\begin{array}{c}\leq 2 \text { Years Old at } \\
\text { Presentation } \\
n=13\end{array}$ & $\begin{array}{c}>2 \text { Years Old at } \\
\text { Presentation } \\
n=12\end{array}$ & $\begin{array}{c}P \\
\text { Value }\end{array}$ & $\begin{array}{l}\text { Males } \\
n=14\end{array}$ & $\begin{array}{c}\text { Females } \\
n=11\end{array}$ & $\begin{array}{c}P \\
\text { Value }\end{array}$ \\
\hline \multicolumn{8}{|l|}{ Treatments } \\
\hline Mean age of first treatment \pm SD & $4.9 \pm 6.5 y$ & $0.5 \pm 0.33 y$ & $9.6 \pm 6.8 y$ & .00072 & $4.5 \pm 7.5 y$ & $5.3 \pm 5.5 y$ & .79 \\
\hline Median age (range) of first treatment & 1.7 y (1 day to 25 y) & 0.33 y (1 day to 1.8 y) & 8.5 y $(3-25 y)$ & & 0.78 y (1 day to 25 y) & $3 y(4 m$ to $16 y)$ & \\
\hline Median treatment procedures (range) & $2(1-5)$ & $3(1-5)$ & $2(1-4)$ & .041 & $2.5(1-5)$ & $2(1-4)$ & .23 \\
\hline Endovascular treatments only & $60 \%$ & $54 \%$ & $67 \%$ & .69 & $57 \%$ & $64 \%$ & 1.0 \\
\hline Any periprocedural complication & $60 \%$ & $85 \%$ & $33 \%$ & .015 & $57 \%$ & $64 \%$ & 1.0 \\
\hline Any symptomatic complication & $32 \%$ & $39 \%$ & $25 \%$ & .67 & $21 \%$ & $45 \%$ & .39 \\
\hline \multicolumn{8}{|l|}{ Outcomes at last follow-up } \\
\hline Mean follow-up duration $\pm S D$ & $3.3 \pm 3.3 y$ & $3.1 \pm 2.8 y$ & $2.7 \pm 3.7 y$ & .74 & $2.3 \pm 2.4 y$ & $4.6 \pm 3.8 y$ & .10 \\
\hline Median (range) follow-up duration & 2 y (1 day to 13 y) & 2 y (1 day to 8 y) & 1 y (2 days to 13 y) & & 1.5 y (1 day to 8 y) & 3.5 y $(0.7-13$ y) & \\
\hline $\begin{array}{l}\text { Occlusion of all targeted arteriovenous } \\
\text { shunts }\end{array}$ & $72 \%$ & $69 \%$ & $75 \%$ & 1.0 & $64 \%$ & $82 \%$ & .41 \\
\hline Elimination of all arteriovenous shunting & $60 \%$ & $62 \%$ & $58 \%$ & 1.0 & $57 \%$ & $64 \%$ & 1.0 \\
\hline White matter calcifications & $25 \%$ & $38 \%$ & $13 \%$ & .34 & $42 \%$ & $0 \%$ & .055 \\
\hline Normal neurologic examination & $48 \%$ & $7.1 \%$ & $92 \%$ & $<.0001$ & $36 \%$ & $64 \%$ & .24 \\
\hline Median last mRS (range) & $1(0-6)$ & $3(0-6)$ & $0(0)$ & .0001 & $2(0-6)$ & $0(0-3)$ & .43 \\
\hline Good outcome (last mRS 0-2) & $72 \%$ & $46 \%$ & $100 \%$ & .0052 & $79 \%$ & $64 \%$ & .66 \\
\hline
\end{tabular}

patients treated in the neonatal period $(8 \%)$ had died at the time of last follow-up (one immediately after treatment and one 3 years later, after being transitioned to comfort care in the setting of severe disability and ventriculoperitoneal shunt fail- 


\begin{tabular}{lccccc}
\hline Table 5: Comparison of posttreatment angiographic and clinical outcomes in pediatric NGAVF and vein of Galen malformation \\
\hline \multicolumn{1}{l}{ NGAVF } & Posterior & Supratentorial & & \\
& Current & Fossa NGAVF & NGAVF & VOGM & VOGM \\
Outcome & Study & Yoshida et al $^{6}$ & Weon et al & Fullerton et al $^{34}$ & Lasjaunias et al $^{33}$ \\
\hline Complete angiographic elimination of arteriovenous shunt & $15 / 25(60 \%)$ & $6 / 14(43 \%)$ & $14 / 35(40 \%)$ & $21 / 27(78 \%)$ & $118 / 216(55 \%)$ \\
Death & $2 / 25(8 \%)$ & $2 / 14(14 \%)$ & $2 / 35(5.7 \%)$ & $4 / 27(15 \%)$ & $23 / 216(11 \%)$ \\
No neurologic deficit or developmental disability & $12 / 25(48 \%)$ & $10 / 14(71 \%)$ & $26 / 35(74 \%)$ & $14 / 27(52 \%)$ & $143 / 216(66 \%)$ \\
\hline
\end{tabular}

ure). Twelve of 25 patients (48\%) were developmentally and neurologically normal at last follow-up (Tables 2, 4, and 5). Good clinical outcome, defined as a last pediatric mRS of 0 to 2 , was achieved in $72 \%$ of patients.

Outcomes differed between age groups at diagnosis, as well as in patients with multi-hole fistulas compared with those with single-hole fistulas. Patients who had a diagnosis of NGAVF before 2 years of age were less likely to have normal neurologic examinations and development than patients diagnosed as children $(7 \%$ versus $92 \%$, respectively, risk ratio = $0.090 ; 95 \% \mathrm{CI}, 0.014$ to $0.59 ; P<.0001$ ). The median last mRS was worse for subjects who originally presented at $\leq 2$ years than for children who originally presented at $>2$ years of age ( 3 versus $0, P=.0001$ ). Whereas all patients with single-hole fistulas ultimately had normal neurologic and developmental outcomes, only $19 \%$ of patients with multi-hole fistulas had a normal clinical outcome $(P=.0001)$. A good clinical outcome (last mRS 0-2) was more common in patients with single-hole fistulas (100\%) than in patients with multi-hole fistulas $(56 \%$, $P=.027)$.

\section{Discussion}

Although NGAVFs are heterogeneous, our data suggest that these lesions can be separated into 2 distinct groups based on the patient's age at presentation and the complexity of AVF angioarchitecture, which are not independent of each other. Patients who present in the first 2 years of life are more likely to harbor large, complex multi-hole AVFs that have high flow arteriovenous shunting leading to CHF. Massive dural venous sinus dilation was also more common in these younger patients with marked arteriovenous shunting. Enlarged persistent fetal venous structures, such as an occipital sinus, also imply that the high-flow shunting observed in multi-hole NGAVFs may begin relatively early in fetal development. ${ }^{19}$

Children presenting after 2 years of age were more likely to have a single-hole NGAVF and to present with seizures, focal neurologic deficits, or intracranial hemorrhage. Other authors have noted that intracranial hemorrhage is an infrequent presentation for NGAVF. ${ }^{1,4,5,16}$ The 3 patients in our series who presented with symptomatic intracranial hemorrhage were older than 3 years of age. Chronicity of arteriovenous shunting may also explain why the 2 patients who had feeding artery aneurysms were also in the older age group. It may require time for arteries exposed to high flow to develop aneurysms, as is described for flow-related aneurysms in adult AVMs. Similarly, chronic exposure of veins to high flow and pressure may cause venous dilation, stenosis, thrombosis, and hemorrhage. The cerebral vasculature of neonates has not been exposed to high flow for as long as that in older children, and might not be expected to have developed feeding artery aneurysms or venous occlusions with their attendant risk of intracranial hem- orrhage. Instead, neonates present with CHF from large shunt fractions before aneurysms and venous occlusions have had a chance to develop.

\section{Comorbidities and Risk Factors}

Comorbidites were identified in almost half of the patients in our series (On-line Table 1), though diagnoses of genetic syndromes were uncommon. Only 1 of our patients was diagnosed with HHT, which contrasts with the experience of the Bicetre group, in which 11 of 41 patients with supratentorial NGAVF were diagnosed with HHT, ${ }^{5}$ and with other literature associating NGAVF with HHT. ${ }^{24,25}$ University of CaliforniaSan Francisco was not an HHT referral center during this retrospective study, and the degree of detail in evaluating firstdegree relatives of patients was heterogeneous. Although the diagnosis of HHT was made in only 1 patient in our cohort, some of these patients could have received the HHT diagnosis elsewhere as adults after their last follow-up at our center. Other authors have reported NGAVF associated with EhlersDanlos syndrome, ${ }^{26,27}$ neurofibromatosis type $\mathrm{I},{ }^{8}$ KlippelTrenaunay-Weber syndrome, ${ }^{28}$ encephalocraniocutaneous lipomatosis, ${ }^{5}$ and aortic coarctation, ${ }^{29}$ none of which were diagnosed in our cohort. Although RASA1 mutations have been associated with brain AVM phenotype, ${ }^{30,31}$ our patients did not undergo testing for this mutation, which is a potential limitation of our study.

\section{Treatment Approach}

Neonatal NGAVFs are particularly difficult to treat. From an endovascular perspective, challenges include the presence of a high-flow fistula, tortuous intracranial feeding arteries, a small femoral artery access site, and limitations in the volume of contrast that can be used. Embolization procedures are often long, with the attendant risk of extended general anesthesia in a critically ill neonate. Before initial embolization in neonates, a brain MR imaging is warranted to assess the degree of underlying encephalomalacia: a severely damaged brain at baseline may prompt a discussion of appropriate goals of care and obviate the need for further intervention.

From a technical perspective, because of the accuracy of embolic deposition at the fistula site and the ability to deploy multiple coils without requiring recatheterization, our group has preferred the use of transarterial coils, as opposed to liquid embolics, in the endovascular treatment of NGAVFs. Compared with the pediatric cohort from Bicetre, our approach is more similar to a recently published series of adult and pediatric patients from Beijing ${ }^{12}$ in which glue or coils followed by glue were favored. ${ }^{5,6,32}$ The use of highly accurate detachable coils may help explain the high overall NGAVF occlusion rate in the current series (Table 5). However, the use of the over- 
the-wire microcatheter technique for coil deployment (as opposed to flow-directed catheterization for $n$-BCA embolization) may also account for the high-if usually asymptomatic_rate of microwire perforations in very young patients in the current series.

Due to small total blood volumes and coexistent CHF, surgery is also risky in neonates. In comparison with the simpler, single-hole arteriovenous shunts that occur in older children, and that are often curable in a single or 2-stage embolization procedure, the presence of multiple arteriovenous shunts in children presenting at $\leq 2$ years of age makes these lesions more likely to require several treatment sessions. Although 7 of 10 surgeries after incomplete embolizations in our cohort occurred before the year 2000, when endovascular techniques were not as well developed, surgical techniques remain an important complement to endovascular therapy, particularly for complex AVFs. Our overall approach for the treatment of NGAVFs in neonates who also have CHF is to perform sufficient embolization to lessen or eliminate CHF, but not necessarily to occlude the entire AVF. Similar to the management of VOGMs, ${ }^{33,34}$ we favor delaying NGAVF treatment until after the first several months of life unless CHF necessitates early intervention.

The goal of eliminating arteriovenous shunting in older children is not for the prevention of CHF but rather to reduce chronic cerebral venous hypertension that can lead to white matter calcification and "melting brain" syndrome, similar to that seen in untreated and insufficiently treated VOGM. ${ }^{33}$ In addition, relief of venous hypertension removes powerful proangiogenic and proinflammatory stimuli, even below the level of venous ischemia. ${ }^{35,36}$

Stereotactic radiosurgery is reserved for patients with NGAVFs who also have an AVM nidus. Radiosurgery has limited ability to induce regression of larger caliber fistulas, and from a practical standpoint, frame placement is not possible in very young patients with open cranial sutures.

\section{Mixed Type Vascular Lesions and De Novo Fistula Formation}

Four patients were found at angiographic follow-up after initial multi-hole NGAVF treatment to have DAVFs that were not previously seen. This raises the question of whether these DAVFs were de novo lesions acquired after NGAVF treatment, perhaps due to activation of angiogenic pathways, or were instead present at initial treatment but masked by the high-flow shunting of the NGAVF. A related phenomenon was observed in 2 patients in our series who were originally thought to have pure single-hole NGAVFs. After coil embolization of their high-flow NGAVFs, a tiny nidus AVM adjacent to the pial NGAVFs was identified, perhaps because elimination of the large arteriovenous shunt allowed angiographic detection of small, nearby low-flow lesions. This also underscores the possibility that some patients diagnosed with pial AVFs actually have nidus AVM components that are difficult to see. This further suggests that pial AVFs may not be a distinct disease from nidal AVMs but that, instead, there is a biologic continuum from nidus angioarchitecture to fistulous architecture.

\section{Clinical Outcomes}

Clinical outcome for patients with NGAVFs appears to depend largely on the complexity of the initial AVF and the age at which patients present clinically. This is not surprising, as the larger the arteriovenous shunt fraction, the more likely the patient is to present in CHF as a neonate. Thus, NGAVFs presenting in neonates and infants might better be compared with VOGMs when counseling parents about disease and treatment outcomes. Similar to patients with VOGMs, younger patients with NGAVFs with more severe disease are more likely to have poor outcomes. ${ }^{37}$ In fact, neonatal NGAVFs appear to have a worse prognosis than VOGMs. ${ }^{2,33,34}$ For single-hole NGAVFs presenting in childhood, however, a more optimistic prognosis is warranted.

\section{Conclusions}

Multihole NGAVFs were more likely to present in neonates with CHF and single-hole NGAVFs predominated in older children presenting with seizures. Overall morbidity of these heterogeneous lesions appears higher than that previously reported for NGAVF, despite a somewhat higher rate of angiographic cure, with most poor outcomes arising in patients presenting with NGAVF at $<2$ years of age.

Disclosures: Steven Hetts—RELATED: Grant: ASNR Foundation Scholar Award, NIH R01 Award, Comments: A clinical trials and epidemiology course partially paid for by those grants allowed me to learn some of the statistical tools I used in this project; UNRELATED: Consultancy: Silk Road Medical, Comments: A biomedical device company not related to the current project. Kevin Keenan-Grant: UCSF School of Medicine Dean's Summer Research Fellowship, Comments: As a UCSF medical student I applied for and was awarded a $\$ 1500$ fellowship from the UCSF School of Medicine to support full-time research work on this project during the summer of 2010. Heather Fullerton-UNRELATED: Board Membership: DSMB for Berlin Heart. Joey English—UNRELATED: Consultancy: Silk Road Medical; Expert Testimony: Emison Hullverson Mitchell, LLP, Comments: Medical legal case reviews and expert witness. Nalin Gupta-UNRELATED: Grants/Grants Pending: NIH, ${ }^{*}$ StemCells Inc.* Christopher Dowd-UNRELATED: Consultancy: Neurovasx; Other: Boston Scientific, Comments: Adjudication committee for clinical study. Michael Lawton-UNRELATED: Royalties: Mizuho America Inc. (* Money paid to institution)

\section{References}

1. Upchurch K, Feng L, Duckwiler GR, et al. Nongalenic arteriovenous fistulas: history of treatment and technology. Neurosurg Focus 2006;20:E8

2. Lasjaunias P, ter Brugge KG, Berenstein A. Cerebral arteriovenous fistulas. In Lasjaunias P, ter Brugge KG, Berenstein A, eds. Surgical Neuroangiography. Berlin, Germany: Springer-Verlag, 2006:227-89

3. Halbach VV, Higashida RT, Hieshima GB, et al. Dural arteriovenous fistulas supplied by ethmoidal arteries. Neurosurgery 1990;26:816-23

4. Tomlinson FH, Rüfenacht DA, Sundt TM Jr, et al. Arteriovenous fistulas of the brain and the spinal cord. J Neurosurg 1993;79:16-27

5. Weon YC, Yoshida Y, Sachet M, et al. Supratentorial cerebral arteriovenous fistulas (AVFs) in children: review of 41 cases with 63 non choroidal singlehole AVFs. Acta Neurochir (Wien) 2005;147:17-31; discussion 31

6. Yoshida Y, Weon YC, Sachet M, et al. Posterior cranial fossa single-hole arteriovenous fistulae in children: 14 consecutive cases. Neuroradiology 2004;46: 474-81

7. Hoh BL, Putman CM, Budzik RF, et al. Surgical and endovascular flow disconnection of intracranial pial single-channel arteriovenous fistulae. Neurosurgery 2001;49:1351-63; discussion 1363-64

8. Andreou A, Ioannidis I, Nasis N. Transarterial balloon-assisted glue embolization of high-flow arteriovenous fistulas. Neuroradiology 2008;50:267-72

9. Kubota T, Nakai H, Tanaka T, et al. A case of intracranial arteriovenous fistula in an infant with neurofibromatosis type 1. Childs Nerv Syst 2002;18:166-70

10. Limaye US, Siddhartha W, Shrivastav M, et al. Endovascular management of intracranial pial arterio-venous fistulas. Neurol India 2004;52:87-90

11. Wang YC, Wong HF, Yeh YS. Intracranial pial arteriovenous fistulas with single-vein drainage. Report of three cases and review of the literature. J Neurosurg 2004;100:201-05

12. Yamashita K, Ohe N, Yoshimura S, et al. Intracranial pial arteriovenous fistula. Neurol Med Chir (Tokyo) 2007;47:550-54 
13. Lv X, Li Y, Jiang C, et al. Endovascular treatment of brain arteriovenous fistulas. AJNR Am J Neuroradiol 2009;30:851-56

14. Wang X, Wang Q, Chen G, et al. Endovascular treatment of congenital brain arteriovenous fistulas with combination of detachable coils and Onyx liquid embolic agent. Neuroradiology 2010;52:1121-26

15. Fatima Z, Ishigame K, Hori M, et al. Time-resolved contrast-enhanced magnetic resonance digital subtraction angiography (MRDSA) in an infant with congenital pial arteriovenous fistula in the brain: a case report. Childs Nerv Syst 2010;26:1121-24

16. Berman MF, Sciacca RR, Pile-Spellman J, et al. The epidemiology of brain arteriovenous malformations. Neurosurgery 2000;47:389-96; discussion 397

17. Vinuela F, Drake CG, Fox AJ, et al. Giant intracranial varices secondary to high-flow arteriovenous fistulae. J Neurosurg 1987;66:198-203

18. Halbach VV, Higashida RT, Hieshima GB, et al. Transarterial occlusion of solitary intracerebral arteriovenous fistulas. AJNR Am J Neuroradiol 1989;10: 747-52

19. Potter CA, Armstrong-Wells J, Fullerton H, et al. Neonatal giant pial arteriovenous malformation: genesis or rapid enlargement in the third trimester. J Neurointerv Surg 2009;1:151-53

20. Barnwell SL, Ciricillo SF, Halbach VV, et al. Intracerebral arteriovenous fistulas associated with intraparenchymal varix in childhood: case reports. Neurosurgery 1990;26:122-25

21. Cooke D, Tatum J, Farid H, et al. Transvenous embolization of a pediatric pial arteriovenous fistula. I NeuroIntervent Surg 2012;4:e14

22. Joint Writing Group of the Technology Assessment Committee American Society of Interventional and Therapeutic Neuroradiology; Joint Section on Cerebrovascular Neurosurgery a Section of the American Association of Neurological Surgeons and Congress of Neurological Surgeons; Section of Stroke and the Section of Interventional Neurology of the American Academy of Neurology, et al. Reporting terminology for brain arteriovenous malformation clinical and radiographic features for use in clinical trials. Stroke 2001;32:1430-42

23. Sanchez-Mejia RO, Chennupati SK, Gupta N, et al. Superior outcomes in children compared with adults after microsurgical resection of brain arteriovenous malformations. J Neurosurg 2006;105:82-87

24. Geibprasert S, Krings T, Armstrong D, et al. Predicting factors for the follow-up outcome and management decisions in vein of Galen aneurysmal malformations. Childs Nerv Syst 2010;26:35-46

25. Kikuchi K, Kowada M, Sasajima H. Vascular malformations of the brain in hereditary hemorrhagic telangiectasia (Rendu-Osler-Weber disease). Surg Neurol 1994;41:374-80

26. Coubes P, Humbertclaude V, Rodesch G, et al. Total endovascular occlusion of a giant direct arteriovenous fistula in the posterior fossa in a case of RenduOsler-Weber disease. Childs Nerv Syst 1996;12:785-88

27. Oya S, Shigeno T, Kumai J, et al. [A case of pial single-channel cerebral arteriovenous fistula]. No Shinkei Geka 2004;32:67-72 [Article in Japanese]

28. Saito A, Sugawara T, Mikawa S, et al. A case of multiple pial arteriovenous fistulas associated with dural arteriovenous fistula. J Neurosurg 2008;109: 1103-07

29. Oyesiku NM, Gahm NH, Goldman RL. Cerebral arteriovenous fistula in the Klippel-Trenaunay-Weber syndrome. Dev Med Child Neurol 1988;30:245-48

30. Tomlinson FH, Piepgras DG, Nichols DA, et al. Remote congenital cerebral arteriovenous fistulae associated with aortic coarctation. Case report. J Neurosurg 1992;76:137-42

31. Eerola I, Boon LM, Mulliken JB, et al. Capillary malformation-arteriovenous malformation, a new clinical and genetic disorder caused by RASA1 mutations. Am J Hum Genet 2003;73:1240-49

32. Revencu N, Boon LM, Mulliken JB, et al. Parkes Weber syndrome, vein of Galen aneurysmal malformation, and other fast-flow vascular anomalies are caused by RASA1 mutations. Hum Mutat 2008;29:959-65

33. Lasjaunias PL, Chng SM, Sachet M, et al. The management of vein of Galen aneurysmal malformations. Neurosurgery 2006;59:S184-94; discussion S3-13

34. Fullerton HJ, Aminoff AR, Ferriero DM, et al. Neurodevelopmental outcom after endovascular treatment of vein of Galen malformations. Neurology 2003;61:1386-90

35. Krings T, Chng SM, Ozanne A, et al. Hereditary hemorrhagic telangiectasia in children: endovascular treatment of neurovascular malformations: results in 31 patients. Neuroradiology 2005;47:946-54

36. Zhu Y, Lawton MT, Du R, et al. Expression of hypoxia-inducible factor-1 and vascular endothelial growth factor in response to venous hypertension. $\mathrm{Neu}$ rosurgery 2006;59:687-96; discussion 687-96

37. Gao P, Zhu Y, Ling F, et al. Nonischemic cerebral venous hypertension promotes a pro-angiogenic stage through HIF-1 downstream genes and leukocyte-derived MMP-9. J Cereb Blood Flow Metab 2009;29:1482-90

38. Halbach VV, Dowd CF, Higashida RT, et al. Preliminary experience with an electrolytically detachable fibered coil. AJNR Am J Neuroradiol 1998;19: $773-77$ 